\title{
Targeted education improves the very low recognition of vertebral fractures and osteoporosis management by general internists
}

\author{
P. Casez • B. Uebelhart • J. -M. Gaspoz • \\ S. Ferrari $\cdot$ M. Louis-Simonet $\cdot$ R. Rizzoli
}

Received: 8 August 2005 / Accepted: 22 December 2005 / Published online: 22 April 2006

(C) International Osteoporosis Foundation and National Osteoporosis Foundation 2006

\begin{abstract}
Introduction: Vertebral fractures in older persons are strong predictors of subsequent fracture risk but remain largely under-recognized. To evaluate the impact of an educational intervention on the recognition of vertebral fractures and the prescription of anti-osteoporosis treatment among general internists, we conducted a prospective study in a service of general internal medicine of a large university teaching hospital in Geneva, Switzerland. During a 3.5-month observation period (phase 1), all lateral spinal or chest radiographs performed on consecutive inpatients over 60 years were reviewed by two independent investigators, and vertebral fractures were graded according to their severity. Methods: Results were compared with radiology reports and general internists' discharge summaries. During the following 2-month intervention period (phase 2), internists were actively educated about vertebral fracture identification by means of lectures, posters and flyers. Radiologists did not receive this educational strategy and served as controls. Results: Among 292 con-
\end{abstract}

Pierre Casez managed the protocol, examined all of the X-rays, collected and analyzed the data, wrote the manuscript. Brigitte Uebelhart examined all the X-rays and contributed to the data analysis and to the writing of the paper. Martine Louis-Simonet, Jean-Michel Gaspoz and Serge Ferrari contributed to the protocol design, participated in the data analysis and to the writing of the paper. René Rizzoli designed the protocol, contributed to the data analysis and to the writing of the paper.

P. Casez $\cdot$ B. Uebelhart

S. Ferrari · R. Rizzoli $(\bowtie)$

Service of Bone Diseases

(WHO Collaborating Centre for Osteoporosis Prevention),

Department of Rehabilitation and Geriatrics,

Geneva University Hospitals,

24 Rue Micheli-du-Crest,

1211 Geneva 14, Switzerland

e-mail: rene.rizzoli@medecine.unige.ch

Tel.: +41-22-3729950

Fax: $+41-22-3729973$

J.-M. Gaspoz · M. Louis-Simonet

General Internal Medicine Service,

Department of Internal Medicine,

Geneva University Hospitals,

Geneva, Switzerland secutive patients (54\% men; range: $60-97$ years) included in phase 1, $85(29 \%)$ were identified by investigators as having at least one vertebral fracture; radiologists detected 29 (34\%), and internists detected 19 (22\%). During the intervention phase, $58(34 \%)$ of 172 patients were identified with vertebral fractures by investigators; radiologists detected 13 patients $(22 \%)$ whereas among internists the detection rate almost doubled (25/58 patients, $43 \% ; p=0.008$ compared to phase 1$)$. The percentage of patients with vertebral fracture who benefitted from an osteoporosis medical management increased from $11 \%$ (phase 1) to $40 \%$ (phase 2, $p<0.03$ ). Conclusion: Our findings confirm the large under-recognition of vertebral fractures, irrespective of their severity, and demonstrate that a simple educational strategy can significantly improve their detection on routine radiographs and, consequently, improve osteoporosis management.

Keywords Education - Fracture risk - Osteoporosis . Vertebral fracture

\section{Introduction}

At the age of 50, the lifetime risk of osteoporotic fractures is greater than $45 \%$ for women and $20 \%$ for men [1]. In addition to being associated with long-term morbidity, decreased quality of life $[2,3]$ and increased mortality [47], osteoporotic fractures are a major risk factor for subsequent fractures [8-10], irrespective of bone mineral density (BMD) [11]. Following a vertebral fracture, $20 \%$ of patients experience a subsequent fracture within 1 year [12]. However, most intervention trials have demonstrated the efficacy of anti-osteoporosis drugs in patients with osteoporosis and at least one prevalent vertebral fracture [13-21].

Patients with a prevalent fragility fracture should therefore be considered to be at high risk for subsequent fractures and be thoroughly evaluated and eventually considered for treatment for osteoporosis. However, diagnostic and/or treatment procedures are rarely initiated after 
low-energy fractures [22-27]. Two retrospective studies on patients suffering from a moderate-to-severe vertebral fracture revealed that the fracture was not recognized on routine radiographs in a large proportion of the patients $(23-40 \%)$ and that even fewer patients had been reported to be suffering from osteoporosis, as noted in the medical chart $(25 \%)$, or to have been treated for osteoporosis $(20$ $24 \%)[28,29]$.

These observations prompted us to prospectively investigate both the prevalence of radiological vertebral fractures in a general internal medicine service and their recognition rate by internists compared to radiologists. We then implemented an educational program targeted to an improved recognition of vertebral fractures and assessed its impact on internists with the aim of increasing the percentage of patients prescribed an anti-osteoporosis drug at discharge.

\section{Methods}

\section{Patients}

Patients of both sexes over 60 years of age who had been admitted to a 100-bed service of General Internal Medicine at the Geneva University Hospitals, Geneva, Switzerland were included in this study. Exclusion criteria were death during hospitalization, Scheuermann's disease, radiologic examination without a radiology report and a radiograph of insufficient quality for analysis.

\section{Vertebral fracture detection}

During an initial observation period of 3.5 months (phase 1), the main investigator (PC) reviewed all lateral chest and lumbar spine radiographs routinely performed in consecutive patients. In the case of multiple hospitalizations during the study period, radiographs obtained during each hospital stay were considered as one observation. Available radiology documents were both numeric and printed on films. Radiographs showing one (or more) vertebral deformity were reviewed by a second independent investigator $(\mathrm{BU})$ to confirm the diagnosis of vertebral fracture.

Vertebral deformities were determined by a validated semiquantitative visual grading [30]. All vertebral deformities of grade 1 or more (loss of vertebral body height $\geq 20 \%$ ) were considered as vertebral fractures. The reasons for choosing a semiquantitative method were its high predictive value for osteoporosis [31] and good correlation with vertebral fracture morphometric determination $[32,33]$ and because radiographic examinations were performed as part of routine care - i.e. for any indication rather than under strict conditions suitable for precise morphometric analyses. Vertebrae from T3 to L2 for chest radiographs and from T11 to L4 for lumbar spine examination were evaluated and classified in four categories: normal: grade 0 (SQ0); mild deformity: grade 1 (SQ1, 20-25\% reduction in height); moderate deformity: grade 2 (SQ2, 25-40\% reduction in height); and severe deformity: grade 3 (SQ3, $>40 \%$ reduction in height). Intra-main-investigator coefficient of variation (kappa) was 0.85 , and inter-investigators' coefficient ranged between 0.69 and 0.78 according to vertebral fracture level and grade.

Radiology reports were screened for reporting of a vertebral fracture, and diagnosis and discharge summaries by general internists were screened for reporting of the following: a vertebral fracture diagnosis; osteoporosis risk factors (age of menopause, fracture history, corticosteroid treatment, alcohol consumption and tobacco use, hyperparathyroidism, hyperthyroidism); prescription of anti-osteoporosis drugs (calcium, vitamin D, bisphosphonates, selective estrogen receptor modulators (SERMs) and hormone replacement therapy); principal diagnosis; co-morbidities abstracted as Charlson comorbidity scores [34]; length of stay. It should be noted that all residents had access to numeric images on their office computers with software allowing modification of brightness and contrast, and zooming.

\section{Educational intervention}

The subsequent 2-month educational intervention (phase 2) included short communications about osteoporosis during rounds, posters illustrating vertebral deformity classification displayed in residents' offices, cartoon-like posters with messages intended to serve as alerts for vertebral fractures hung on residents' office doors (and changed every 2 weeks) and flyers with vertebral deformity classification and a vertebral fracture management algorithm distributed to all residents. To assess the impact of the intervention on internists' ability to report vertebral fractures, we estimated the probability that for each patient with one or more vertebral fracture, the internist would specify the diagnosis in the medical report.

\section{Statistical analysis}

Patient characteristics and the percentage with prevalent vertebral fractures detected by radiologists and general internists, respectively, are presented as means \pm standard deviation (SD). The Chi-square test was used to compare the percentage of patients with prevalent vertebral fractures identified through radiology reports and residents' discharge summaries with the percentage of patients with prevalent vertebral fractures identified by the investigators, the percentage of patients identified by internists before and after the educational program (phase 1 vs. phase 2 ) and patient characteristics between the two phases. Furthermore, we built a logistic regression model to estimate the odds of vertebral fracture detection between the two phases and related this to the independent effects of the intervention and multiple covariates (age, sex, number of vertebral fractures, history of fracture, history of corticoid use, history of neoplasia, vertebral fracture grade and Charlson comorbidity index score). Analyses were performed with EPIINFo6 v. 6.04dfr software [CDC, World Health Organi- 


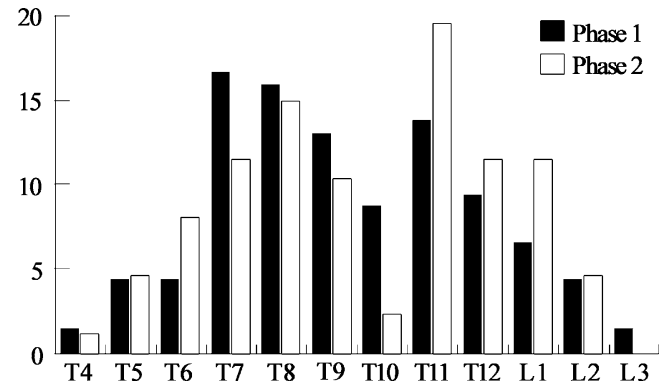

Fig. 1 Distribution of vertebral fracture (in percentages). There was no difference between phases 1 and 2

zation (WHO)] and Stata 7.0 software (Stata, College Station, Tex.); $p<0.05$ was chosen as the minimal level of significance.

\section{Role of the funding source}

The funding source had no role in study design, data collection, data analysis, data interpretation, writing of the report or the decision to submit this report for publication.

\section{Results}

During the 5.5-month study period, 2403 patients $\geq 60$ years old were admitted to the General Internal Medicine wards at the Geneva University Hospitals, of whom 698 had lateral chest or lumbar radiographic examinations for multiple purposes. Of these 698 patients, we excluded those who died during hospitalization $(n=27,3.9 \%)$ and those with radiography of insufficient quality for analysis $(n=35,5 \%)$ and with missing radiology reports (radiograph performed in the emergency ward; $n=172,24.6 \%$ ). Ultimately, $464(66 \%)$ of the 698 eligible patients were included in the analysis: 292 during phase 1 (observation) and 172 during phase 2 (education).

Characteristics of patients with vertebral fractures

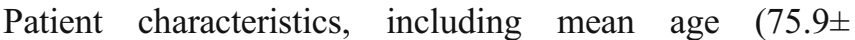
8.6 years), age distribution, gender, principal diagnoses, co-morbidities (Charlson score), history of fracture and corticoid treatment (past or present), were similar in both phases (data not shown). One hundred and forty-three (31\%) patients had at least one vertebral deformity of grade 1 or more: 85 in phase 1 and 58 in phase 2 .

Vertebral deformities were more frequent in the midthoracic and thoraco-lumbar junction regions and were similarly distributed in phases 1 and 2 (Fig. 1). Fractured and not fractured patients differed by age $(78.6 \pm 8.7$ vs. $74.6 \pm 8.40$ years, respectively; $p<0.001$ ) and by history of fracture [odds ratio (OR) for patients with history of a fracture compared to those without: $5.6 ; p<0.001]$. Differences for corticosteroid use (current or past) were close to significance (OR for patients using corticosteroids compared to those who were not: $1.7 ; p=0.062$ ).

\section{Detection rate among internists and radiologists}

During phase 1 , the number of patients with at least one vertebral fracture as determined by the investigators was $29 \%$ overall and $20 \%$ when only grade 2 or higher fractures were taken into consideration. The percentage of subjects with prevalent vertebral fractures reported by radiologists was slightly higher than that reported by the internists $(34$ vs. $22 \%$, respectively; $p=0.088$ ). When only deformities of grade 2 and higher were considered, the corresponding values were 46 and $31 \%$, respectively (Table 1). Several clinical risk factors influenced the probability of detecting patients with vertebral fractures. Hence, the odds for vertebral fracture recognition were higher for women and for fractures of grade 2 or more, in patients with a history of fracture and in patients with corticosteroid therapy, but multiple fractures did not influence their detection (Table 2). In addition, vertebral fracture at the thoracic vertebra T9 was more frequently recognized by internists than those at other locations ( $p<0.009$; data not shown). In contrast, diagnosis of neoplasia did not significantly influence recognition rates (Table 2). It is noteworthy that only two patients were diagnosed as having vertebral fractures by radiologists but not by the investigators (falsepositive): in one case, the apparent fracture was explained by the presence of severe scoliosis and in the other, by an image artifact due to the presence of bronchopneumonia.

Table 1 Number of patients with identified vertebral fractures classified by the study phases and the doctors' specialty

\begin{tabular}{|c|c|c|c|c|c|c|}
\hline & \multicolumn{2}{|l|}{ Phase 1} & \multicolumn{4}{|l|}{ Phase 2} \\
\hline & $\begin{array}{l}\text { Investigators } \\
n(\%)\end{array}$ & $\begin{array}{l}\text { Radiologists } \\
n(\%)\end{array}$ & $\begin{array}{l}\text { Internists } \\
n(\%)\end{array}$ & $\begin{array}{l}\text { Investigators } \\
n(\%)\end{array}$ & $\begin{array}{l}\text { Radiologists } \\
n(\%)\end{array}$ & $\begin{array}{l}\text { Internists } \\
n(\%)\end{array}$ \\
\hline All vertebral fractures & $85(100)$ & $29(34)$ & $19(22)$ & $58(100)$ & $13(22)$ & $25(43) *$, ** \\
\hline SQ2-SQ3 only & $59(100)$ & $27(46)$ & $18(31)$ & $44(100)$ & $11(25)^{* * *}$ & $24(55)^{*}, * *$ \\
\hline SQ3 only & $29(100)$ & $16(55)$ & $11(38)$ & $18(100)$ & $5(28)$ & $9(50)$ \\
\hline
\end{tabular}

$* p<0.02$ as compared with the radiologist recognition rate in phase 2

$* * p<0.01$ and $* * * p<0.03$ as compared with phase 1 in the corresponding specialty group 
Table 2 Adjusted odds ratio (OR) of correct diagnosis of vertebral fractures by internists and radiologists (CI 95\% 95\% confidence interval)

\begin{tabular}{|c|c|c|c|c|c|c|}
\hline & \multicolumn{3}{|c|}{ Internists } & \multicolumn{3}{|c|}{ Radiologists } \\
\hline & OR & CI $95 \%$ & $p$ & OR & CI $95 \%$ & $p$ \\
\hline \multicolumn{7}{|l|}{ Age range (years) } \\
\hline $60-69$ & 1 & - & - & 1 & - & - \\
\hline $70-79$ & 0.8 & $0.2-3.7$ & 0.797 & 1.1 & $0.3-3.9$ & 0.872 \\
\hline $80-89$ & 1.2 & $0.3-5.3$ & 0.799 & 1.0 & $0.3-3.5$ & 0.996 \\
\hline Number of vertebral fractures (per additional fracture) & 1.2 & $0.8-1.9$ & 0.413 & 0.9 & $0.6-1.3$ & 0.646 \\
\hline History of fracture $\mathrm{a}^{\mathrm{a}}$ & 4.8 & $1.8-12.7$ & 0.001 & - & - & - \\
\hline Corticosteroid use $^{\mathrm{b}}$ & 5.1 & $1.4-17.9$ & 0.012 & - & - & - \\
\hline Neoplasia $^{\mathrm{b}}$ & 0.6 & $0.2-2.3$ & 0.614 & - & - & - \\
\hline Vertebral fracture grade ( $\geq 2$ vs. 1$)$ & 16.8 & $3.29-86.2$ & 0.001 & 5.9 & $1.8-19.2$ & 0.003 \\
\hline
\end{tabular}

${ }^{\mathrm{a}} \mathrm{Leg}$, hip, rib, arm and forearm fracture history

${ }^{\mathrm{b}}$ Past or present

Impact of the educational intervention on vertebral fracture detection

During phase 2, the overall prevalence of vertebral fractures as determined by the investigators was $34 \%$ (26\% for grade $\geq 2$ ). Meanwhile, general internists exposed to a targeted educational program significantly improved their recognition rate of vertebral fractures, which increased from $22 \%$ in phase 1 to $43 \%$ ( $p \leq 0.008$ compared with phase 1). Hence, the odds for vertebral fracture detection following the introduction of the educational program were as high as 4.5 compared to the detection rate preintervention (Table 2). In contrast, radiologists not exposed to the educational program (controls) maintained a low rate of detection during this period ( $22 \% ; p<0.02 \mathrm{vs}$. internists). When only vertebral deformities of grade 2 and higher were taken into consideration, the corresponding detection rates were 55\% (internists) and 25\% (radiologists) ( $p<0.02$ for comparison) (Table 1). This improvement in reporting patients with vertebral fractures among internists resulted primarily from a better detection that had not previously been identified by radiologists ( 7 vs. $28 \%$ before and after education, respectively; $p<0.001)$. This observation shows that internists were examining and evaluating the radiologic images independently of the radiology reports and that their ability to newly diagnose vertebral fractures had been improved by the teaching program. In addition, the proportion of fractures determined from radiology reports that internists subsequently reported in the discharge summary (45 and $69 \%$ before and after education, respectively) also tended to improve (Fig. 2).

This educational strategy also modified the way in which internists reported vertebral fractures in their discharge summary. Whereas only $11 \%(2 / 19)$ of vertebral fractures recognized by internists correctly qualified as "fractures" during phase $1,56 \%(14 / 25)$ were correctly identified in their discharge summaries during phase $2(p<0.002)$. Meanwhile, no significant changes occurred among radiologists who adequately defined less than $8 \%$ of vertebral fractures identified as "fractures" in their reports.

Most importantly, the percentage of patients with vertebral fracture who benefitted from an osteoporosis medical management [prescription of examinations (chemistry, dual energy x-ray absorptiometry) to investigate bone disease or the adequate prescription of drugs against osteoporosis] significantly increased from $11 \%$ (phase 1 ) to $40 \%$ (phase $2, p<0.03$ ).

\section{Discussion}

In this prospective study conducted at a large university teaching hospital, we confirmed that prevalent vertebral fractures on routine lateral radiographs of chest and lumbar spine remain largely under-recognized by both radiologists and general internists. Detection rates of patients with at least one moderate-to-severe fracture $(46 \%)$ was a little less than that found by Majumdar and colleagues (60\%) [29]

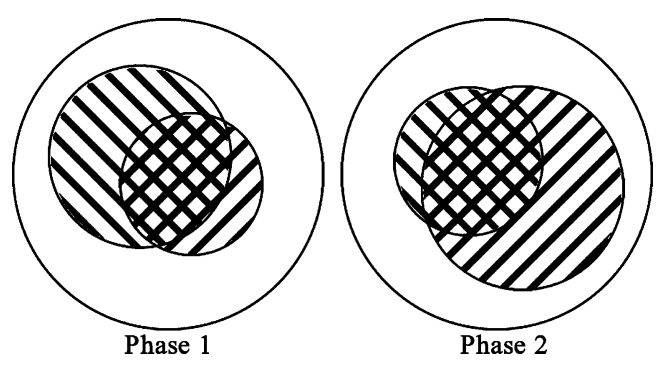

Fig. 2 Vertebral fracture recognition. White bars patients with vertebral fracture detected by investigators, diagonally-striped bars (high-left to low-right) percentage of patients detected by radiologists, but not by general internists, diagonally-striped bars (highright to low-left) percentage of patients detected by general internists, but not radiologists, diamond-marked bars percentage of patients detected by both general internist residents and radiologists. In phase 2 , the percentage of vertebral fractures reported by general internists but not by radiologists was significantly higher $(p<0.001)$ 
but approximately the same as that found by Gehlbach in his retrospective study (52\%) [28]. An assessment of the impact of an educational intervention program targeted to vertebral fracture recognition among internists showed that the identification of fracture patients improved by approximately twofold. Furthermore, the percentage of patients with vertebral fracture who benefitted from an osteoporosis medical management increased from $11 \%$ (phase 1) to $40 \%$ (phase $2 ; p<0.03$ ), indicating that the educational intervention had led to a greater awareness and knowledge of the disease. The high prevalence of patients older than 60 years of age with vertebral fractures in this prospective study is in keeping with results from a previous retrospective survey performed in a similar setting [28]. It is also compatible with large epidemiological studies on vertebral fracture incidence in the aging population $[2,35]$. A low awareness of osteoporosis and its complications by both patients and doctors has been consistently found. Hence, not only vertebral fractures but also fractures of the proximal femur do not lead to consistent modifications in patient management [2, 22, 24-27]. This is also true for forearm fractures, for which only a minority of patients receive appropriate investigation and treatment [23].

The twofold or more increase in the risk of subsequent osteoporotic fractures associated with prevalent vertebral deformities $[1,9,11,12]$ strongly indicates that the identification of vertebral fractures represents an important step towards an osteoporosis case-finding strategy. The yield of such a strategy is similar or even superior to the screening of BMD by dual X-ray absorptiometry [36]. Taken together with the evidence that vertebral fracture also predicts the response to anti-osteoporosis therapy [37], it may be emphasized that upon admission to hospital, patients older than 60 years should be considered to be at high risk of osteoporosis and that their routine radiographs should be examined accordingly.

However, our study has several limitations. Patients were admitted to the hospital for an acute illness, for which routine radiographic examinations were performed. In this context, it is understandable that low-grade vertebral deformities - i.e. SQ1 - would be less easily detected. Even restricting our analysis to vertebral fractures of higher grades, such as SQ2 and SQ3 in which the decrease in vertebral body height is greater than $25 \%$, still showed a detection rate of $50 \%$ or less. It remains possible, therefore, that both radiologists and general internists actually detected vertebral fractures but were not reporting them because their focus was primarily on the main diagnosis leading to hospitalization. In addition, we cannot exclude that the educational intervention led to a higher reporting rather than a higher recognition of vertebral fractures. Nevertheless, by using the radiologists as a control group not exposed to targeted education, we were able to demonstrate that the educational program encouraged internists to self-analyze the radiographic documents and not to only rely on radiology reports. Moreover, our intervention also triggered higher anti-osteoporosis treatment rates, thus suggesting that the recognition of vertebral fracture as a hallmark of osteoporosis was truly assimilated among internists. However it should not be underemphasized that about one-half of the vertebral fractures detected by the investigators still remained unidentified according to the internists' discharge summaries.

We were also unable to evaluate whether the improved recognition rate of vertebral fractures will be maintained after the end of the intervention. Considering that most general internists at a major teaching hospital are in training and rotate from one service to another, it would probably be necessary to periodically reinforce such intervention programs to maintain a high rate of vertebral fracture detection.

In conclusion, from a cost-effectiveness perspective [15], under-recognition of vertebral fractures on routine radiographic examinations represents the loss of a great opportunity to identify patients at high risk of fracture who may benefit from osteoporosis treatment. In that perspective, a major effort should be devoted to implement vertebral fracture recognition in postgraduate teaching programs for both radiologists and general internists [38].

Acknowledgements We are indebted to the members of the Department of Radiology for their collaboration. We thank Dr. M. Kossovsky for his valuable help in the statistical analysis, and Mrs. R. Sudan for her careful reading of the manuscript. This survey was made possible thanks to grants from the Geneva University Hospitals (support of the investigator). Rene Rizzoli had full access to all of the data in the study and takes the responsibility for the integrity of the data and the accuracy of the data analysis.

\section{References}

1. Kanis JA, Johnell O, Oden A, Sembo I, Redlund-Johnell I, Dawson A, De Laet C, Jonsson B (2000) Long-term risk of osteoporotic fracture in Malmo. Osteoporos Int 11:669-674

2. Cummings SR, Melton LJ (2002) Epidemiology and outcomes of osteoporotic fractures. Lancet 359:1761-1767

3. Ross PD (1997) Clinical consequences of vertebral fractures. Am J Med 103:30S-42S; discussion 42S-43S

4. Cauley JA, Thompson DE, Ensrud KC, Scott JC, Black D (2000) Risk of mortality following clinical fractures. Osteoporos Int 11:556-561

5. Center JR, Nguyen TV, Schneider D, Sambrook PN, Eisman JA (1999) Mortality after all major types of osteoporotic fracture in men and women: an observational study. Lancet 353:878-882

6. Hasserius R, Karlsson MK, Nilsson BE, Redlund-Johnell I, Johnell O (2003) Prevalent vertebral deformities predict increased mortality and increased fracture rate in both men and women: a 10-year population-based study of 598 individuals from the Swedish cohort in the European Vertebral Osteoporosis Study. Osteoporos Int 14:61-68

7. Kado DM, Browner WS, Palermo L, Nevitt MC, Genant HK, Cummings SR (1999) Vertebral fractures and mortality in older women: a prospective study. Study of Osteoporotic Fractures Research Group. Arch Intern Med 159:1215-1220

8. Kanis JA, Johansson H, Oden A, Johnell O, De Laet C, Eisman JA, McCloskey EV, Mellstrom D, Melton LJ 3rd, Pols HA, Reeve J, Silman AJ, Tenenhouse A (2004) A family history of fracture and fracture risk: a meta-analysis. Bone 35:1029-1037

9. Klotzbuecher CM, Ross PD, Landsman PB, Abbott TA 3rd, Berger M (2000) Patients with prior fractures have an increased risk of future fractures: a summary of the literature and statistical synthesis. J Bone Miner Res 15:721-739 
10. Ross PD, Genant HK, Davis JW, Miller PD, Wasnich RD (1993) Predicting vertebral fracture incidence from prevalent fractures and bone density among non-black, osteoporotic women. Osteoporos Int 3:120-126

11. Kanis JA, Borgstrom F, De Laet C, Johansson H, Johnell O, Jonsson B, Oden A, Zethraeus N, Pfleger B, Khaltaev N (2004) Assessment of fracture risk. Osteoporos Int 16:581-589

12. Lindsay R, Silverman SL, Cooper C, Hanley DA, Barton I, Broy SB, Licata A, Benhamou L, Geusens P, Flowers K, Stracke H, Seeman E (2001) Risk of new vertebral fracture in the year following a fracture. JAMA 285:320-323

13. Black DM, Thompson DE, Bauer DC, Ensrud K, Musliner T, Hochberg MC, Nevitt MC, Suryawanshi S, Cummings SR (2000) Fracture risk reduction with alendronate in women with osteoporosis: the Fracture Intervention Trial. FIT Research Group. J Clin Endocrinol Metab 85:4118-4124

14. Chevalley T, Rizzoli R, Nydegger V, Slosman D, Rapin CH, Michel JP, Vasey H, Bonjour JP (1994) Effects of calcium supplements on femoral bone mineral density and vertebral fracture rate in vitaminD-replete elderly patients. Osteoporos Int 4:245-252

15. Delmas PD (2002) Treatment of postmenopausal osteoporosis. Lancet 359:2018-2026

16. Harris ST, Watts NB, Genant HK, McKeever CD, Hangartner T, Keller M, Chesnut CH 3rd, Brown J, Eriksen EF, Hoseyni MS, Axelrod DW, Miller PD (1999) Effects of risedronate treatment on vertebral and nonvertebral fractures in women with postmenopausal osteoporosis: a randomized controlled trial. Vertebral Efficacy With Risedronate Therapy (VERT) Study Group. JAMA 282:1344-1352

17. Hauselmann HJ, Rizzoli R (2003) A comprehensive review of treatments for postmenopausal osteoporosis. Osteoporos Int $14: 2-12$

18. Neer RM, Arnaud CD, Zanchetta JR, Prince R, Gaich GA, Reginster JY, Hodsman AB, Eriksen EF, Ish-Shalom S, Genant HK, Wang O, Mitlak BH (2001) Effect of parathyroid hormone (1-34) on fractures and bone mineral density in postmenopausal women with osteoporosis. N Engl J Med 344:1434-1441

19. Recker RR, Hinders S, Davies KM, Heaney RP, Stegman MR, Lappe JM, Kimmel DB (1996) Correcting calcium nutritional deficiency prevents spine fractures in elderly women. J Bone Miner Res 11:1961-1966

20. Reginster J, Minne HW, Sorensen OH, Hooper M, Roux C, Brandi ML, Lund B, Ethgen D, Pack S, Roumagnac I, Eastell R (2000) Randomized trial of the effects of risedronate on vertebral fractures in women with established postmenopausal osteoporosis. Vertebral Efficacy with Risedronate Therapy (VERT) Study Group. Osteoporos Int 11:83-91

21. Siris E, Adachi JD, Lu Y, Fuerst T, Crans GG, Wong M, Harper KD, Genant HK (2002) Effects of raloxifene on fracture severity in postmenopausal women with osteoporosis: results from the MORE study. Multiple Outcomes of Raloxifene Evaluation. Osteoporos Int 13:907-913

22. Bellantonio S, Fortinsky R, Prestwood K (2001) How well are community-living women treated for osteoporosis after hip fracture? J Am Geriatr Soc 49:1197-1204
23. Freedman KB, Kaplan FS, Bilker WB, Strom BL, Lowe RA (2000) Treatment of osteoporosis: are physicians missing an opportunity? J Bone Joint Surg Am 82-A:1063-1070

24. Juby AG, Davis P (2001) A prospective evaluation of the awareness, knowledge, risk factors and current treatment of osteoporosis in a cohort of elderly subjects. Osteoporos Int 12:617-622

25. Kamel HK, Hussain MS, Tariq S, Perry HM, Morley JE (2000) Failure to diagnose and treat osteoporosis in elderly patients hospitalized with hip fracture. Am J Med 109:326-328

26. Kiebzak GM, Beinart GA, Perser K, Ambrose CG, Siff SJ, Heggeness MH (2002) Undertreatment of osteoporosis in men with hip fracture. Arch Intern Med 162:2217-2222

27. Staeger P, Burnand B, Santos-Eggimann B, Klay M, Siffert C, Livio JJ, Burckhardt P, Paccaud F (2000) Prevention of recurrent hip fracture. Aging 12:13-21

28. Gehlbach SH, Bigelow C, Heimisdottir M, May S, Walker M, Kirkwood JR (2000) Recognition of vertebral fracture in a clinical setting. Osteoporos Int 11:577-582

29. Majumdar SR, Kim N, Colman I, Chahal AM, Raymond G, Jen H, Siminoski KG, Hanley DA, Rowe BH (2005) Incidental vertebral fractures discovered with chest radiography in the emergency department: prevalence, recognition, and osteoporosis management in a cohort of elderly patients. Arch Intern Med 165:905-909

30. Genant HK, Wu CY, van Kuijk C, Nevitt MC (1993) Vertebral fracture assessment using a semiquantitative technique. J Bone Miner Res 8:1137-1148

31. Szulc P, Munoz F, Marchand F, Delmas PD (2001) Semiquantitative evaluation of prevalent vertebral deformities in men and their relationship with osteoporosis: the MINOS study. Osteoporos Int 12:302-310

32. Genant HK, Jergas M, Palermo L, Nevitt M, Valentin RS, Black D, Cummings SR (1996) Comparison of semiquantitative visual and quantitative morphometric assessment of prevalent and incident vertebral fractures in osteoporosis The Study of Osteoporotic Fractures Research Group. J Bone Miner Res 11:984-996

33. Grados F, Roux C, de Vernejoul MC, Utard G, Sebert JL, Fardellone P (2001) Comparison of four morphometric definitions and a semiquantitative consensus reading for assessing prevalent vertebral fractures. Osteoporos Int 12:716-722

34. Charlson ME, Pompei P, Ales KL, MacKenzie CR (1987) A new method of classifying prognostic comorbidity in longitudinal studies: development and validation. J Chronic Dis 40:373-383

35. Melton LJ 3rd, Kan SH, Frye MA, Wahner HW, O'Fallon WM, Riggs BL (1989) Epidemiology of vertebral fractures in women. Am J Epidemiol 129:1000-1011

36. Kanis JA, Johnell O (2005) Requirements for DXA for the management of osteoporosis in Europe. Osteoporos Int 16:229-238

37. Delmas PD, Genant HK, Crans GG, Stock JL, Wong M, Siris E, Adachi JD (2003) Severity of prevalent vertebral fractures and the risk of subsequent vertebral and nonvertebral fractures: results from the MORE trial. Bone 33:522-532

38. Lenchik L, Rogers LF, Delmas PD, Genant HK (2004) Diagnosis of osteoporotic vertebral fractures: importance of recognition and description by radiologists. A J R Am J Roentgenol 183:949-958 